\title{
NOR association in Canis familiaris
}

\author{
M Rønne, BS Poulsen, Y Shibasaki \\ Odense University, Institute of Medical Biology, \\ Department of Anatomy and Cytology, Campusvej 55, DK-5230 Odense M, Denmark
}

(Proceedings of the 9th European Colloquium on Cytogenetics of Domestic Animals; Toulouse-Auzeville, 10-13 July 1990)

nucleolar organizer region (NOR) / RBG-bands / association / dog

\section{INTRODUCTION}

The domestic dog has 78 chromosomes (Gustavsson, 1964). Because of the large number of chromosomes of almost similar size and morphology, a precise analysis of the karyotype is rather difficult (Howard-Peebles and Pryor, 1980; Manolache et al, 1976; Wurster-Hill and Centerwall, 1982). However, a G-banded karyotype of Canis lupus (Wayne et al, 1987), which is supported to be homologue to that of Canis familiaris, displayed detailed information about banding patterns and served as a guideline for the numbering system used in the RBG-banded karyotype (Poulsen et $a l$, in press) and in the present study. Several authors have reported on the nucleolar organizer regions (NORs) and NOR associations in the karyotype of the domestic $\operatorname{dog}$ (Kopp et al, 1982a, b; Pathak et al, 1982). In this paper, the frequencies of NOR associations and the localization of NORs in the female karyotype of Canis familiaris are presented using sequential RBG-banding and the silver (Ag)-NOR staining technique.

\section{MATERIALS AND METHODS}

The donor animals were selected at random from the laboratory Beagles at the Institute of Biomedicine, Odense University. Peripheral blood samples from 3 female dogs were cultured and processed for RBG-band induction as previously described (Rønne 1985; Poulsen et al, in press). Ag-NOR staining was modified after Howell and Black (1980) and used to stain previously RBG-banded metaphases.

From each donor animal, 10 selected RBG-banded metaphase and prometaphase plates with good spreading and well-defined bands were photographed, registered and karyotyped according to Poulsen et al (in press). The selected metaphase and prometaphase plates were subsequently silver-stained to display active NORs and rephotographed after counter-staining with 3\% Giemsa solution in Sørensen's phosphate buffer ( $\mathrm{pH} \mathrm{8.0)}$ ) for $5 \mathrm{~min}$. Comparison between donor animals showed the same NOR pattern for all 3 animals. Forty RBG-banded metaphase and 
prometaphase plates selected at random from all 3 donor animals were photographed and registered. These cells were then silver-stained, counter-stained with Giemsa and rephotographed. Metaphase and prometaphase plates with corresponding R-band and NOR-staining were compared. The locations of active NORs and NOR associations were determined.

\section{RESULTS}

A total of 40 randomly selected metaphases were sequentially examined with RBGbanding and Ag-NOR staining. Eight autosomes, 5, 8, 14, 16, 19, 21, 32, 37, carry NORs in the telomeric regions (fig 1). The late-replicating $\mathrm{X}$ chromosome also showed an active telomeric NOR (Xq) in $10 \%$ of the examined metaphases (fig 2 ). Twenty-one metaphases displayed NOR association among the autosomes at a range of 1-3 associations per metaphase. The $\mathrm{X}$ chromosomes were not involved in any NOR association. As shown in table I, chromosomes $14(38.46 \%)$ and 16 $(19.23 \%)$ have remarkably high levels of involvement in NOR association. Typical NOR associations are shown in figure 3.

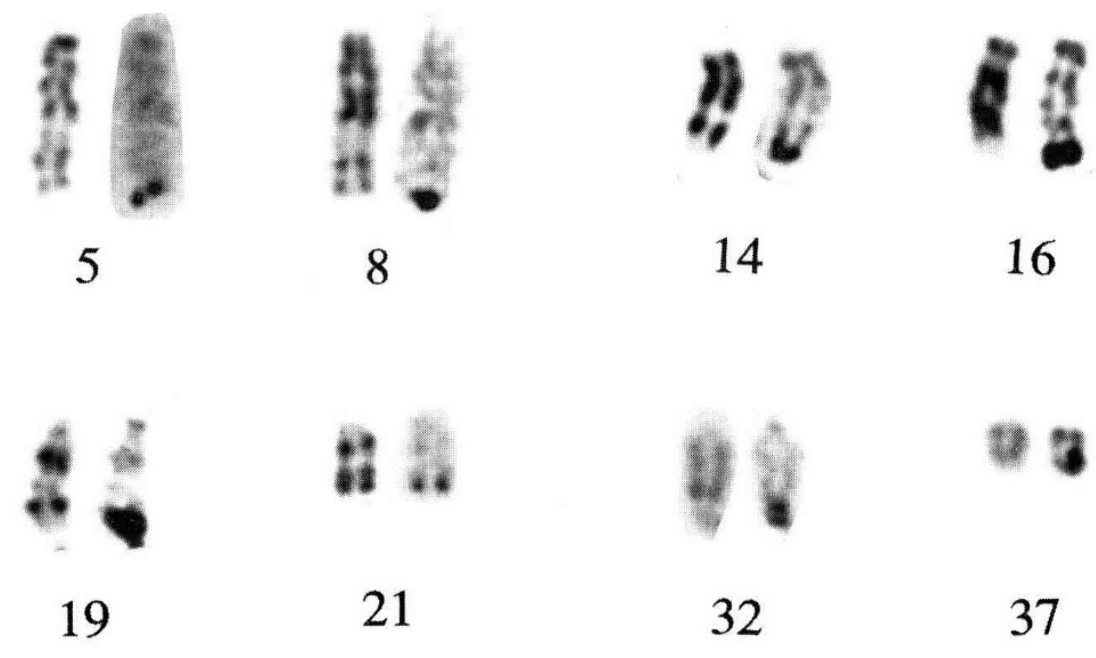

Fig 1. The 8 representative autosomes of the dog carrying active NORs after fluorescence plus Giemsa (FPG)-staining (left side) and subsequent $\mathrm{Ag}$-NOR staining (right side).

\section{DISCUSSION}

Several authors have described NORs in domestic dog (Kopp et al, 1982a, b; Pathak et al, 1982; Howard-Peebles and Howell, 1983). Since the dog karyotype is not standardized, the reported positions of NORs on dog chromosomes were inconsistent. Howard-Peebles and Howell (1983) published that the maximum number of NORs in the dog karyotype was 8 , including the NOR on the Y chromosome. Using high-resolution RBG-banding (Poulsen et al, in press), NORs 


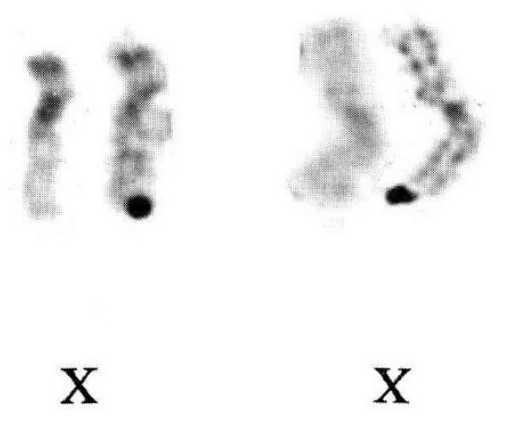

Fig 2. The late-replicating $X$ chromosomes of the domestic dog showing silver-positive NOR (right side) on the telomere of the q-arm.
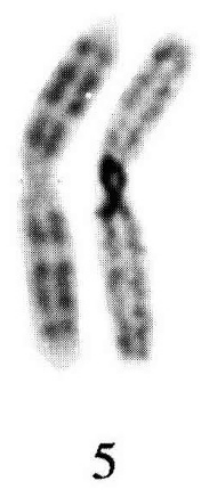

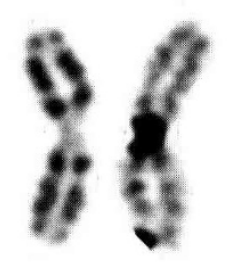

14

Fig 3. Typical NOR associations observed in dog karyotypes (right side). When stained only with Giemsa (left side), they look like metacentric chromosomes.

Table I. The number and frequency of 26 identified NOR associations between autosomes.

\begin{tabular}{ccccccccccc}
\hline $\begin{array}{c}\text { Chromosome } \\
\text { number }\end{array}$ & 5 & 8 & 14 & 16 & 19 & 21 & 32 & 37 & Total & Frequency \\
\hline 5 & 1 & & & 1 & & & & 1 & 3 & 5.77 \\
8 & & & 2 & & 1 & 1 & 1 & & 5 & 9.62 \\
14 & & 2 & $3^{\mathrm{a}}$ & $8^{\mathrm{a}}$ & & 3 & 2 & 2 & 20 & 38.46 \\
16 & 1 & & $8^{\mathrm{a}}$ & & & 1 & & & 10 & 19.23 \\
19 & & 1 & & & & 1 & & & 2 & 3.85 \\
21 & & 1 & 3 & 1 & 1 & & & & 6 & 11.54 \\
32 & 1 & 1 & 2 & & & & & & 3 & 5.77 \\
37 & 1 & & 2 & & & & & & 3 & 5.77 \\
Total & & & & & & & & & 52 & 100.01 \\
\hline
\end{tabular}

a NOR association (14-14-16) was counted as 14-14, 14-16, 14-16. 
on 8 different autosomes were observed (fig 1). In males, Pathak et al (1982) and Kopp et al (1982b) reported that the $\mathrm{Y}$ but not the $\mathrm{X}$ chromosome displayed active NORs. Late-replicating $\mathrm{X}$ chromosomes bearing silver grains were observed at a low frequency (10\%) after Ag-NOR staining (fig 2). However, at this stage, further investigation of a larger population is needed to determine the presence and role of NORs on sex chromosomes in the dog.

As previously reported by Kopp et al (1982a), we observed a high incidence (50\%) of metaphases with NOR association. NOR-associated chromosomes may look like metacentrics as shown in figure 3. Translocations in normal dog (Larsen et al, 1978, 1979; Mayr et al, 1986; Ma and Gilmore, 1971; Welling and Strandström 1988), dog cancer (Grindem and Buoen, 1986; Benjamin and Noronha, 1967; Oshimura et al, 1973; Else et al, 1982; Welling et al, 1988) and other abnormalities (Shive et al, 1965; Hare et al, 1967) were reported after using conventional Giemsa-stained or Gbanded chromosomes. Especially in cancer studies (Mellink et al, 1989), metacentric chromosomes have been used as markers of neoplastic development. Without using NOR staining, however, there is a high risk of confusing NOR association with true translocation.

\section{REFERENCES}

Benjamin SA, Noronha F (1967) Cytogenetic studies in canine lymphosarcoma. Cornell Vet 57, 526-542

Else RW, Norval M, Neill WA (1982) The characteristics of a canine mammary carcinoma cell line, REM 134. Br $J$ Cancer 46, 675-681

Grindem CB, Buoen LC (1986) Cytogenetic analysis of leukaemic cells in the dog. A report of 10 cases and a review of the literature. J Comp Pathol 96, 623-635

Gustavsson I (1964) The chromosomes of the dog. Hereditas 51, 187-189

Hare WCD, Wilkinson JS, McFeely RA, Riser WH (1967) Bone chondroplasia and a chromosome abnormality in the same dog. Am J Vet Res 28, 583-587

Howard-Peebles PN, Pryor JC (1980) The R-banding pattern of the canine karyotype. $J$ Hered 71, 361-362

Howard-Peebles PN, Howell WM (1983) Nucleolus organizer regions of the canine karyotype. Cytogenet Cell Genet 35, 293-294

Howell WM, Black DA (1980) Controlled silver-staining of nucleolus organizer regions with a protective colloidal developer: a 1-step method. Experientia 36, 1014-1015

Kopp E, Mayr B, Schleger W (1982a) Nucleolus organizer regions on chromosomes of the domestic dog. $J$ Hered 73, 73

Kopp E, Mayr B, Schleger W (1982b) Nucleolus organizer regions on chromosomes of the domestic dog. J Hered 73, 230

Larsen RE, Dias E, Cervenka J (1978) Centric fusion of autosomal chromosomes in a bitch and offspring. Am $J$ Vet Res 39, 861-864

Larsen RE, Dias E, Flores G, Selden JR (1979) Breeding studies reveal segregation of a canine Robertsonian translocation along Mendelian proportions. Cytogenet Cell Genet 24, 95-101

Ma NSF, Gilmore CE (1971) Chromosomal abnormality in a phenotypically and clinically normal dog. Cytogenetics 10, 254-259

Manolache M, Ross WM, Schmid M (1976) Banding analysis of the somatic chromosomes of the dog (Canis familiaris). Can J Genet Cytol 18, 513-518 
Mayr B, Krutzler J, Schleger W, Auer H (1986) A new type of Robertsonian translocation in the domestic dog. $J$ Hered 77,127

Mellink CHM, Bosma AA, Rutteman GR (1989) Chromosome abnormalities in a case of canine metastatic mammary carcinoma. Proceedings of the 8th European Colloquium on Cytogenetics of Domestic Animals Bristol (Long S, ed) 115-121

Oshimura M, Sasaki M, Makino S (1973) Chromosomal banding patterns in primary and transplanted venereal tumors of the dog. J Natl Cancer Inst 51, 1197-1203

Pathak S, van Tuinen P, Merry DE (1982) Heterochromatin, synaptonemal complex, and NOR activity in the somatic and germ cells of a male domestic dog, Canis familiaris (Mammalia, Canidae). Cytogenet Cell Genet 34, 112-118

Poulsen BS, Shibasaki Y, Rønne M (1991) Banding studies in Canis familiaris. I. Replication patterns in karyotypes from lymphocyte cultures. Cytobios, in press

Rønne M (1985) Double synchronization of human lymphocyte cultures: selection for high resolution banded metaphases in the first and second division. Cytogenet Cell Genet 39, 292-295

Shive RJ, Hare WCD, Patterson DF (1965) Chromosome studies in dogs with congenital cardiac defects. Cytogenetics 4, 340-348

Wayne RK, Nash WG, O'Brien SJ (1987) Chromosome evolution of the Canidae. I. Species with high diploid numbers. Cytogenet Cell Genei 44, 123-133

Welling J, Strandström H (1988) Unbalanced Robertsonian translocations in canine lymphocytes and bone marrow cells in vitro. Hereditas 109, 193-196

Welling J, Strandström H, Knuutila S (1988) Lymphatic leukaemia cell line 3447 from the dog. A karyotypic analysis. Hereditas 109, 185-191

Wurster-Hill DH, Centerwall WR (1982) The interrelationships of chromosome banding pattern in canids, musterids, hyena, and felids. Cytogenet Cell Genet 34, 178-192 